\title{
Exhaust Emissions of a Medium Power Diesel Engine Operated with Biodiesel
}

\author{
Nicolae Cordoş ${ }^{1, a}$, Adrian Todorut ${ }^{2, b}$, István Barabás ${ }^{3, c}$ \\ 1,2,3 Automotive Engineering Department, \\ Technical University of Cluj-Napoca, \\ B-dul Muncii, nr. 103 - 105, postal code 400641, Cluj-Napoca, Romania; \\ ancordos@yahoo.com (corresponding author); badrian.todorut@auto.utcluj.ro; \\ istvan.barabas@auto.utcluj.ro
}

Keywords: rapeseed methyl ester, diesel engine, fuel blends, cetane number, viscosity, emissions

\begin{abstract}
The purpose of this study was to identify from experimental researches the results regarding the nitrogen oxides $\left(\mathrm{NO}_{\mathrm{x}}\right)$ emissions and hydrocarbon emissions $(\mathrm{HC})$, emissions of a four-stroke, four cylinder, direct injection of a Romanian medium power diesel tractor engine at partial loads operating on diesel fuel (DF), rapeseed methyl ester (RME), degummed and filtered (5 $\mu \mathrm{m})$ pure rapeseed oil (RO100) and its blends with diesel fuel: 20\% pure rapeseed oil-80\% diesel fuel (RO20), 50\% pure rapeseed oil-50\% diesel fuel (RO50), 75\% pure rapeseed oil-25\% diesel fuel (RO75) compared to diesel fuel. The main properties of the tested fuels (density, kinematic viscosity, oxidation stability, acid value, peroxide number, coke content, water content and cetane number) have been determined. The value of $\mathrm{NO}_{\mathrm{x}}$ emissions for the experimented biofuels is smaller up to $53 \%$ (for RO100) and increases up to $37 \%$ (for RO75) for different engine loads as compared to the diesel fuel. The $\mathrm{HC}$ emission shows a decrease for all biofuels used in the experiment ranging between 4\% (for RO100) and 63\% (RO75) at different loads relative to the diesel fuel.
\end{abstract}

\section{Introduction}

There are four potential ways to use vegetable oil as fuel for diesel engines. One is to convert vegetable oil in a product with similar properties to diesel fuel (oil changes chemical structure). This process is called transesterification. Another method is to use pure vegetable oil (filtered only) and mixed with different proportions with standard diesel fuel. Another method relies on the diesel fuel mixture with methyl ester of oil and the fourth method is to use pure vegetable oil (filtered) in diesel engines. This method requires implementing diesel engine changes because of the higher viscosity of vegetable oil (e.g. fuel heater). The temperature influence on viscosity is more significant for fuels with a higher cinematic viscosity, that has been explained by Barabás and Todoruţ [1] in that the activation energy for the viscous flow is higher for vegetal oils and biodiesel in comparison with diesel. Due to the high viscosity and low volatility of vegetable oils, the brake thermal efficiency of vegetable oils is inferior to that of diesel. This leads to problems such as high smoke, $\mathrm{HC}$ and $\mathrm{CO}$ emissions [2]. All vegetable oils are extremely viscous, with viscosities ranging from 10 to 17 times higher than diesel fuel [3]. The exhaust gas emissions of the vegetable oil used as fuel compared to diesel oil receive the most attention in the literature. Pollutant emissions are classified in two categories: conventional pollutants regulated worldwide since 1970, and specific pollutants whose emission levels are low, but attract particular attention given their toxic nature or their harmful environmental effects [4].

Rapeseed oil has been tried successfully to run a diesel engine [5,6]. The main advantages of vegetable oils as diesel engine fuel are: the availability, renewability, lower sulphur and aromatic content, and biodegradability. They also provide sustainability, reduction of green house gas emissions, regional development, and improvement in agriculture [7]. Pure rapeseed oil as a cheap 
and convenient alternative in conventional diesel engines has hardly been promoted because of some technical problems related to its high density, viscosity, poor filtration and low volatility [8, 9]. In Europe, one of the most popular renewable fuels is rapeseed methyl ester (RME) because its usage in Diesels contributes to a reduction of ambient air pollution by achievement of the global $\mathrm{CO}_{2}$ cycle [10]. Mixing RME with Diesel fuel improves the lubricating properties of the fuel blends to compensate for the reduced sulphur content in Diesel fuel, which has been lowered from 2000 ppm to 200-500 ppm in recent years [11].

Emission tests with rapeseed fuelled tractor Deutz-Fahr (162 PS) on the test bench show that limiting values of $\mathrm{CO}, \mathrm{HC}$ and particulate matter of EURO norms for rapeseed oil and diesel fuel are met, but the emission of $\mathrm{NO}_{\mathrm{x}}$ with rapeseed oil fuel is up to $14 \%$ higher than the limiting value [12]. Labeckas and Slavinskas [13] have find that the maximum $\mathrm{NO}_{\mathrm{x}}$ emissions increase with the mass percent of oxygen in the blend and are higher by $9.2 \%, 20 \%$ and $5.1 \%$ for rapeseed oil and its blends RO75 and RO50. Emissions of hydrocarbons (HC) remain on a considerably low level ranging between 8 and $16 \mathrm{ppm}$ whereas during engine operation on pure rapeseed oil they roughly approach to zero level. Peterson and Reece [14] used several blends of diesel fuels with both ethyl and methyl esters from rapeseed oil in vehicles equipped with similar $5900 \mathrm{cc}$ engines. They measured within this diesel engine the reductions in $\mathrm{NO}_{\mathrm{x}}$ emissions of around $10 \%$ both with ethyl and methyl ester blends. The same authors have obtained reductions up to $50 \%$ of the $\mathrm{HC}$ emissions, using these pure biodiesel fuels. Alam et al. [15] found a $60 \%$ reduction of $\mathrm{HC}$ with their biodiesel in a 6-cylinder diesel engine.

The aim of this paper is to determine and observe the evolution of the $\mathrm{NO}_{\mathrm{x}}$ and $\mathrm{HC}$ emissions in the case of using the fuels based on rapeseed oil on a medium-power diesel engine at different engine loads and engine speed as compared to diesel fuel.

\section{Material and Experimental Procedure}

In this study, the diesel engine was fuelled with 6 different fuel blends: $100 \%$ diesel fuel (DF); $100 \%$ rapeseed methyl ester (RME); $80 \%$ diesel fuel - 20\% pure rapeseed oil (RO20); 50\% diesel fuel - 50\% pure rapeseed oil (RO50); 25\% diesel fuel 75\% pure rapeseed oil (RO75); 100\% pure rapeseed oil (RO100). The main properties of the tested fuels have been determined and are presented in Table 1.

Table 1. The main properties of the tested fuels

\begin{tabular}{llllllll}
\hline Property parameters & DF & RME & RO20 & RO50 & RO75 & RO100 & Test methods \\
\hline Density, $\left[\mathrm{g} / \mathrm{cm}^{3}\right]$ & 0.834 & 0.883 & 0.855 & 0.880 & 0.897 & 0.915 & $\begin{array}{l}\text { SR EN ISO } \\
3675\end{array}$ \\
& 2.346 & 4.466 & 4.424 & 9.654 & 17.859 & 34.358 & ASTM D445 \\
\hline Kinematic viscosity $\left(40{ }^{\circ} \mathrm{C}\right),\left[\mathrm{mm}^{2} / \mathrm{s}\right]$ & $>58$ & 6.84 & $>58$ & 9.5 & 7.79 & 5.92 & ISO 6886 \\
\hline Oxidation stability, $[\mathrm{h}]$ & 0.04 & 0.292 & 0.625 & 1.358 & 1.904 & 2.008 & DIN 51558 \\
\hline Acid value, $[\mathrm{mg} \mathrm{KOH} / \mathrm{g}]$ & 0 & 3.13 & 2.13 & 5.20 & 6.33 & 13.59 & ISO 3960 \\
\hline Peroxide number, $\left[\mathrm{mmol} \cdot \mathrm{O}_{2} / \mathrm{kg}\right]$ & 0.009 & 0.022 & 0.078 & 0.183 & 0.259 & 0.4 & ASTM D524-76 \\
\hline Coke content, $[\mathrm{max} \mathrm{wt} \%]$ & 37 & 77 & 138 & 297 & 405 & 535 & ISO 12937 \\
\hline Water content, $[\mathrm{mg} / \mathrm{kg}]$ & 57.6 & 50.3 & 56 & 53.8 & 49.3 & 48.1 & ASTM D613 \\
\hline Cetane number & & & &
\end{tabular}

Figure 1 shows the variation of kinematic viscosity with temperature (from $20^{\circ} \mathrm{C}$ to $100^{\circ} \mathrm{C}$ ) for the tested fuels.As a result of the experimental research on the influence of temperature on the kinematic viscosity it can be noticed that the higher the temperature is, the smaller the viscosity of tested fuels becomes. The higher the concentration of the rapeseed oil is in the blends, the higher the viscosity and density will be. Viscosity affects the engine system supply and the fuel spraying process into the combustion chamber. The increase of viscosity is disfavoring spraying and the fuel burning in the engine. A fuel too viscous will worsen the formation of an air-fuel mixture, because the droplets are larger and penetrant and will reach to the wall of combustion chamber. Thus, it turns into a white smoke with a pungent odor (due to incomplete combustion products: aldehydes and acids). In contrast, low-viscosity fuels, which favor a fine spray, the droplets mass being smaller, the penetration of the jet in denser air is insufficient. It forms a black smoke, characteristic for the lack of oxygen (burning occurs with excess fuel). 


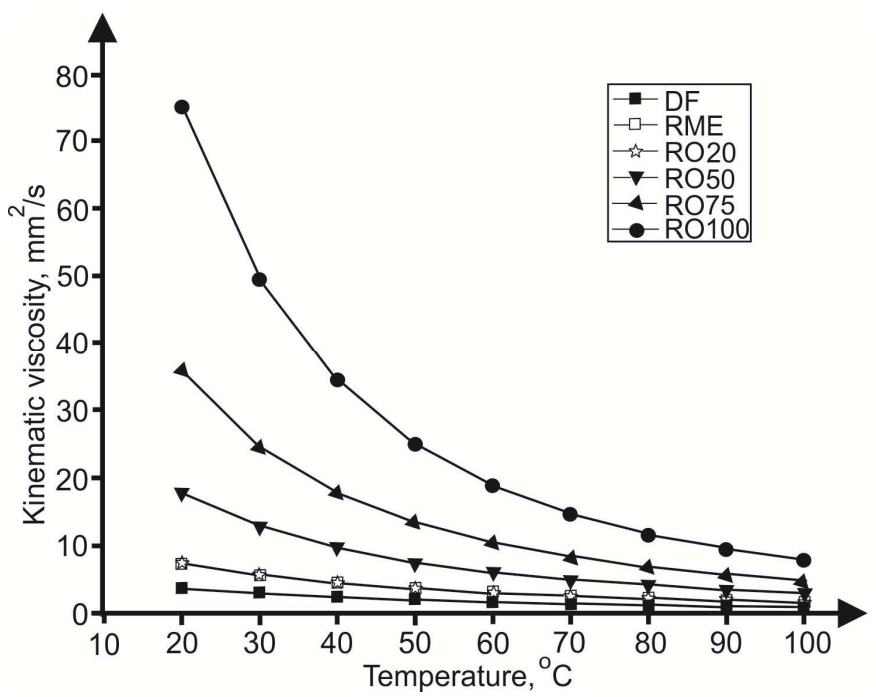

Fig. 1. Variation of kinematic viscosity with temperature for the experimented fuels.

According to the Quality Standard for Rapeseed Oil [16] the kinematic viscosity of RO100 at $40^{\circ} \mathrm{C}$ is about $38 \mathrm{~mm}^{2} / \mathrm{s}$ as maxim value while in this study the kinematic viscosity of RO100 at $40^{\circ} \mathrm{C}$ is $34.35 \mathrm{~mm}^{2} / \mathrm{s}$. The given results are in good agreement with study made by Labeckas and Slavinskas [13] where it has been determined that the viscosity of pure rapeseed oil at $20^{\circ} \mathrm{C}$ is $78.6 \mathrm{~mm}^{2} / \mathrm{s}$ and in this study the kinematic viscosity at $20^{\circ} \mathrm{C}$ is $75.03 \mathrm{~mm}^{2} / \mathrm{s}$. As the temperature increases, the viscosity of rapeseed oil decreases significantly.

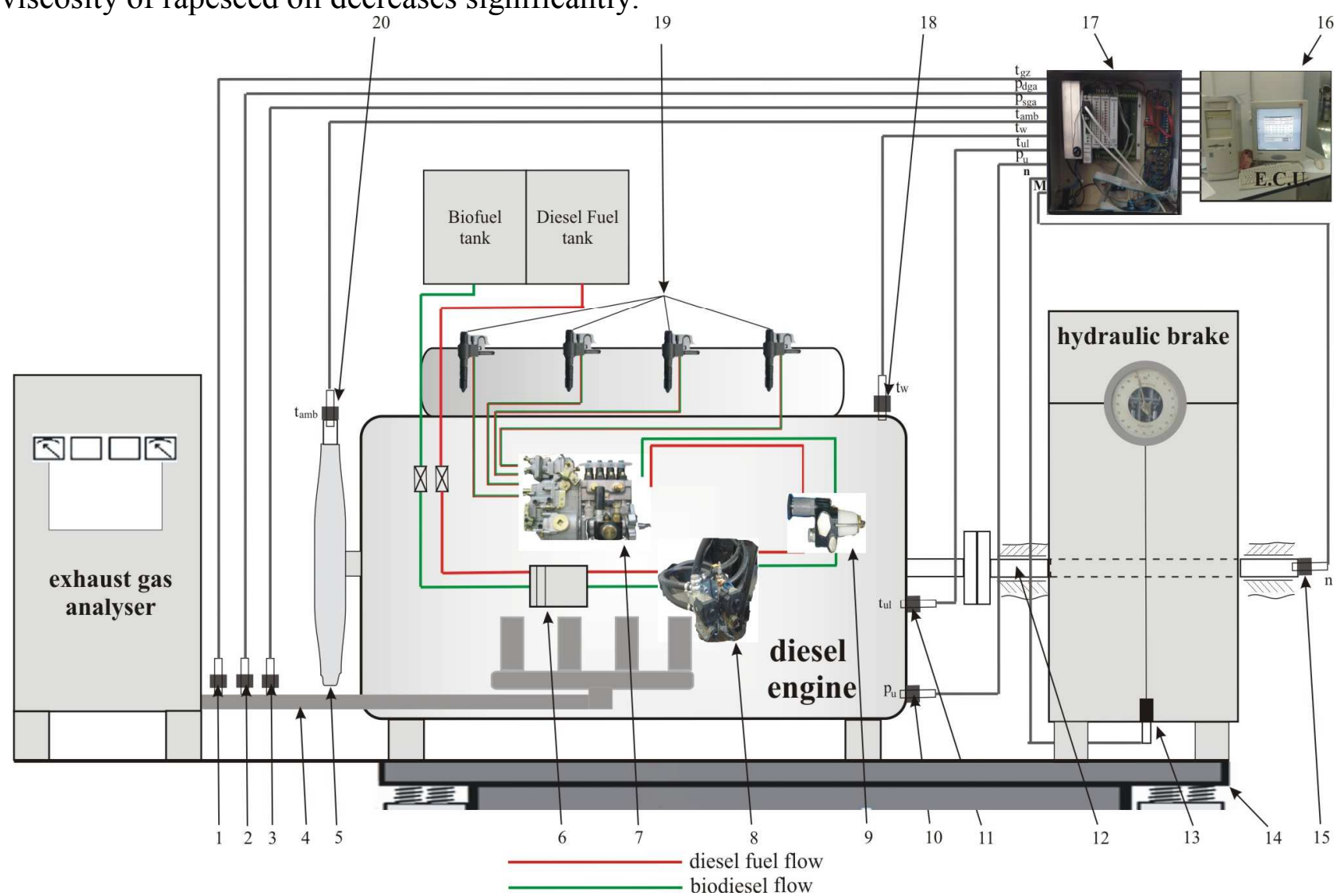

Fig. 2. Experimental stand and sensor positioning scheme.

1 - exhaust gas temperature sensor; 2 - exhaust gas dynamic pressure sensor 3- exhaust static pressure sensor ; 4 exhaust pipe; 5 - engine radiator; 6 - switch distributor; 7 - in-line pump injection; 8 - biofuel heating element; 9- pump supply; 10- oil pressure sensor; 11- oil temperature sensor; 12 - hydraulic brake shaft; 13 - engine torque sensor; 14 shock absorbers 15- rotation sensor; 16 - electronic computing unit; 17- electronic block (multiplexer module); 18water temperature sensor; 19- injectors; 20 - ambient temperature sensor. 
The experimental stand (Figure 2) equipped with a tractor diesel engine D-2402 type (4 cylinders, engine capacity $4760 \mathrm{~cm}^{3}$, compression ratio $17: 1$, effective power $51.5 \mathrm{~kW}$, injection pressure $17.5 \pm 5 \mathrm{MPa}$, brake specific fuels consumption $244 \mathrm{~g} / \mathrm{kWh}$, Compression ratio 17:1), hydraulic brake, exhaust analyzer type BEA 350 DTM (the device can measure $\mathrm{NO}_{\mathrm{x}}$ and $\mathrm{HC}$ emissions as ppm with an $0.001 \%$ accuracy), sensors that measure the instantaneous values of some parameters and data acquisition system, allows the measurement of engine speed, braking force, fuel consumption, testing duration coolant engine temperature, oil temperature and ambient parameters. The experiments were started firstly with diesel fuel baseline data were recorded after the engine reached the operating temperature. The engine was loaded at wide open accelerator position, and ran at different speeds between 1200 and $1950 \mathrm{rpm}$ and different engine loads: $90 \%, 85 \%, 80 \%$, $75 \%, 70 \%$ and $65 \%$. The engine speed and load were recorded from the digital indicator of the test ring.

\section{Results and Discussion}

Figure 3 illustrates the variation of $\mathrm{NO}_{\mathrm{x}}$ emissions, in percentages, for different engine loads and engine speed in comparison with diesel fuel. The variation of $\mathrm{NO}_{\mathrm{x}}$ emissions of the fuels based on rapeseed oil varies for values higher than DF with up to $37 \%$ (for RO75 at the engine load of $75 \%$ and engine speed of $1600 \mathrm{rpm}$ ) and minimum values of up to $-53 \%$ for RO100 (load $65 \%$ and engine speed of $1200 \mathrm{rpm}$ ).

It can be noticed that, as the engine loads increase, the tendency of $\mathrm{NO}_{\mathrm{x}}$ emissions increases relative to DF. The observed $\mathrm{NO}_{\mathrm{x}}$ emissions increases appeared to have been induced as the results increases in the temperature of the combustion chamber at high loads. For the engine loads $65 \%$ and $70 \%$, a more emphasized tendency of decrease in biofuels emissions can be noticed in comparison with DF. This can be explained due to the thermal regime of the engine, which grows while its load increases and its engine speed decreases. Meanwhile, the dosage of fuel in the combustion chamber is increased, thus obtaining much higher ignition temperatures. Thus, the $\mathrm{NO}_{\mathrm{x}}$ emissions have a tendency to grow according to the engine's load. This tendency of $\mathrm{NO}_{\mathrm{x}}$ growing can be also noticed in the experiments conducted by Barabás et al. [17] on the same engine, and Labeckas and Slavinskas [18] on a 4-cylinders diesel engine, the cylindrical capacity of $4750 \mathrm{~cm}^{3}$ and injection pressure of $17.5 \pm 0,5 \mathrm{MPa}$ having $59 \mathrm{~kW}$.

RO100 insures a significant decrease of $\mathrm{NO}_{\mathrm{x}}$ emissions on all the 6 engines loads and all engine speeds relative to the diesel fuel. These results are in conformity with the experiments conducted with different vegetable oils by other authors. For instance, as a result of the research conducted by Dorado et al. [19] with olive oil, there has been a decrease of $\mathrm{NO}_{\mathrm{x}}$ emissions up to $20 \%$ compared to diesel and Lapuerta et al. [20] used biodiesel from the sunflower on a diesel engine of $1900 \mathrm{~cm}^{3}$, resulting in a decrease in $\mathrm{NO}_{\mathrm{x}}$ emissions. Bhupendra et al. [21] found that the levels of $\mathrm{NO}_{\mathrm{x}}$ from Jatropa oil during the entire experiment on a Kirloskar diesel engine were lower than those from the diesel fuel and on the same engine, Saravanan et al. [22] found that the fuel injection timing is an influencing factor in reducing the $\mathrm{NO}_{\mathrm{x}}$ emissions. He obtained a decrease of $\mathrm{NO}_{\mathrm{x}}$ emissions of crude rice bran oil by $20.27 \%$, as compared to the diesel fuel. The decrease of $\mathrm{NO}_{\mathrm{x}}$ emissions of RO100 might be explained by the fact that, even if the oxygen content is higher for biodiesel, due to the smaller caloric value of RO100, the temperature in the burning chamber will be lower, thus obtaining smaller $\mathrm{NO}_{\mathrm{x}}$ emissions. The evolution of $\mathrm{NO}_{\mathrm{x}}$ emissions for $\mathrm{RME}$ varies from $-28 \%$ (for the load $70 \%$ and engine speed $1550 \mathrm{rpm}$ ) up to $26 \%$ (for the load $85 \%$ and revolution $1800 \mathrm{rpm}$ ). The trials conducted by Gwi-Taek et al. [23] on a mono-cylinder engine show that the $\mathrm{NO}_{\mathrm{x}}$ emissions are slightly higher when using RME relative to diesel. The growth tendency of the $\mathrm{NO}_{\mathrm{x}}$ emissions have also been proved by Labeckas and Slavinskas [10] who noticed that once the RME's concentration in diesel increases, $\mathrm{NO}_{\mathrm{x}}$ increases, as well.

The test made on a 2 cylinder diesel engine (Deutz AG F2L511) with RME by Lebedevas et. al. [24] show an increase of the $\mathrm{NO}_{x}$ emissions of up to 17\%. Raslavičius and Bazaras [25] found that the $\mathrm{NO}_{\mathrm{x}}$ value increases by $10.4 \%$ for the $\mathrm{B} 100$ from rapeseed oil. 
The rapeseed oil mixtures with diesel RO20, RO50, RO75 insure an obvious decrease of emissions relative to DF for low engine loads (65\% and 70\%) up to $26 \%$ for RO20 (at engine load of $70 \%$ and
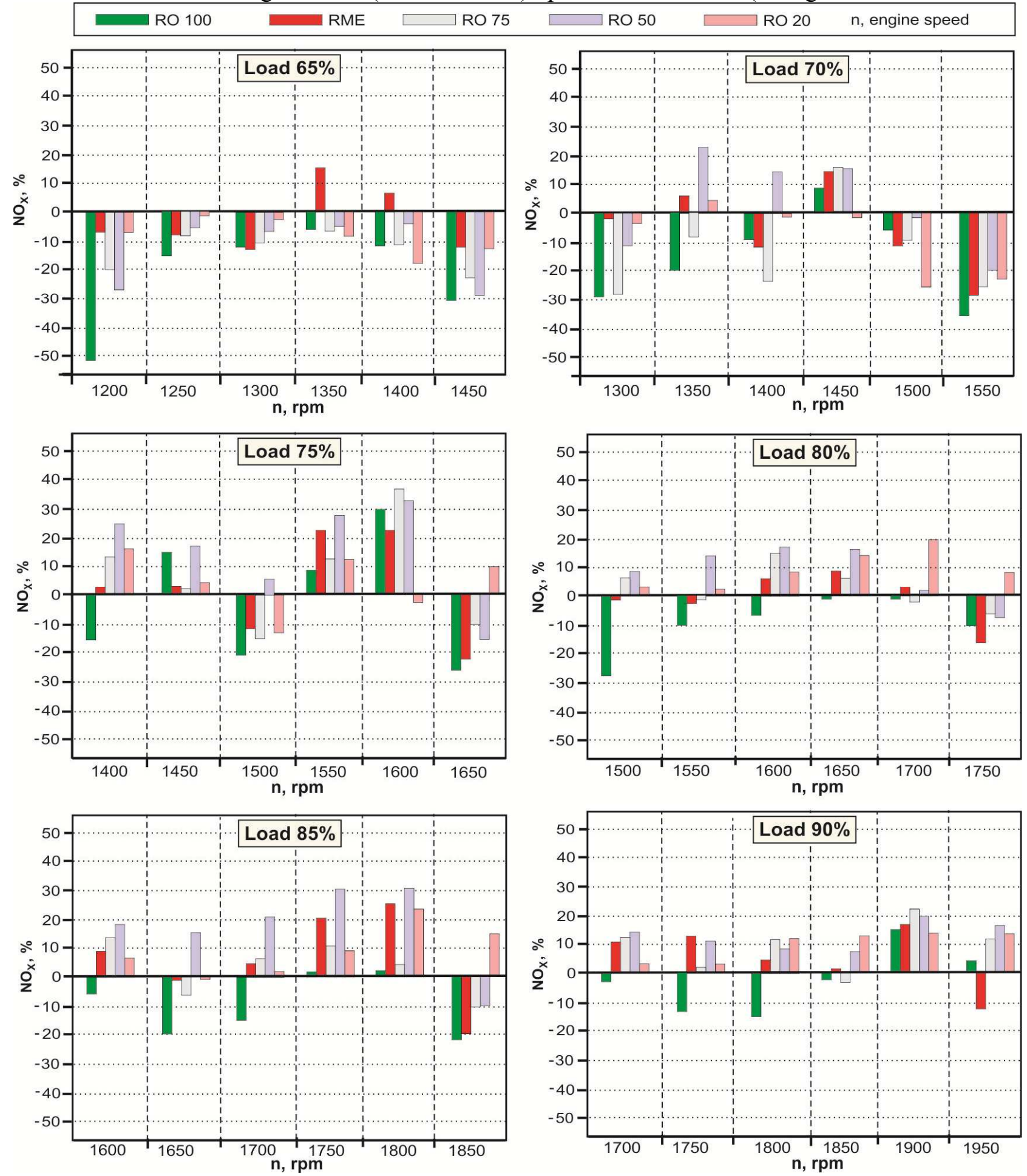

Fig. 3. $\mathrm{NO}_{\mathrm{x}}$ emissions as a function of load at various engine speeds relative to the diesel fuel.

$1500 \mathrm{rpm}$ ), 29\% for RO50 (at engine load of $65 \%$ and $1450 \mathrm{rpm}$ ), and $28 \%$ for RO75 (at engine load of $70 \%$ and $1300 \mathrm{rpm}$ ). This decrease of the $\mathrm{NO}_{\mathrm{x}}$ emissions takes place according to the experiments conducted by Labeckas and Slavinskas [13], whereafter a decrease of $\mathrm{NO}_{\mathrm{x}}$ for the fuels RO75, RO50 and RO25 of 20\%, 21\% and $37 \%$ respectively was noticed.

The decrease of the $\mathrm{NO}_{\mathrm{x}}$ emissions can probably be achieved due to the small quantity of pre-mixed fuel for the fast reactions in the first stage of the burning process, which leads to the decrease of the temperature within the engine cylinder. This emissions decrease might also be possible due to the smaller calorific power of the rapeseed oil. 
According to the facts presented by Graboski and McCornick [9], $\mathrm{NO}_{\mathrm{x}}$ emissions increase significantly for both neat and blended vegetable oil derived fuels in both two and four stroke engines. These tendencies were observed and verified during the experiments made by Raslavičius and Strakšas [26] on a four cycled tractor diesel engine D144 type with a biodiesel obtained from rapeseed oil. They obtained a level of $\mathrm{NO}_{\mathrm{x}}$ emissions for all the tested biofuels (B100 and RO) or compounded blends (B50/dB50) of average 5.1\% to 12.2\% higher than those of diesel fuel.

In Figure 2, it can be seen that within the range of tests, the $\mathrm{NO}_{\mathrm{x}}$ emissions from rapeseed oil mixture with DF are higher at high loads. This is probably due to the increased fuel inlet temperature. The growth of the $\mathrm{NO}_{\mathrm{x}}$ emissions can be explained by the higher number of peroxides contained by the rapeseed oil. The peroxide mixtures include a class of combinations that are characterized by the presence of a O-O group, which means that the rapeseed oil has a high content of oxygen, this being a proven fact. During the formation process of nitrogen oxides at the beginning of burning, there appear many points of flames, distributed in depth. The oxygen surrounding the nucleus of the flame immediately consums itselfs, relative to the further areas, where it keeps its initial concentration. These areas are submitted to heating by the increase of pressure and the heat radiated by the flame. The nitrogen oxides form within these last areas, due to the fact that oxygen has a higher concentration here and the temperature is high. The weight of the areas where the oxygen maintained its initial concentration reduces during the burning. Even if the temperature of the gases increases, the speed formation of nitrogen oxides decreases. This means that the majority of the nitrogen oxides that appear at the end within the exhaustion gases form relatively sooner during the burning process.

Figure 4 shows the evolution of $\mathrm{HC}$ emissions in the case of fuels based on rapeseed oil in comparison with diesel fuel.

The hydrocarbons (HC) in the exhaustion gases are due to the conditions firstly determined by the impossibility of propagation of the flame front in the fuel mixture. When the fuel reaches the wall of the burning chamber, it suffers slow chemical transformations with hydrocarbons formations due to insufficient burning. Another cause for the hydrocarbons formation is the fact that the fuel drops do not get enough oxygen. This explains the fact that the rapeseed oil, having a percentage of oxygen $(\sim 10 \%)$ has smaller hydrocarbons emissions, for most of the functioning regimes relative to the diesel fuel, which does not contain oxygen. The high content of peroxides in the rapeseed oil has also a positive influence on the formation of hydrocarbons emissions [26].

Usually, the HC emissions for all biofules show tendencies towards decrease for most engine loads at different engine speeds in comparison with the diesel fuel. Most results show a decrease in the $\mathrm{HC}$ emissions when substituting conventional diesel fuel with biodiesel fuels [27,28]. The EPA review [29] shows a 70\% mean reduction of $\mathrm{HC}$ emissions with pure biodiesel with respect to conventional diesel. RO 100 has an evolution of $\mathrm{HC}$ emissions between $-53 \%$ (for engine load of $65 \%$ at $1200 \mathrm{rpm}$ ) and $+8.5 \%$ (for load of $80 \%$ at $1700 \mathrm{rpm}$ ).

The majority of $\mathrm{HC}$ emissions for RME have smaller values in comparison with DF. These decreases are between $8 \%$ (for the engine load of $70 \%$ and $1350 \mathrm{rpm}$ ) and $60.5 \%$ (for the engine load of $80 \%$ and $1550 \mathrm{rpm}$ ). According to Lebedevas et. al. [23], RME has a reduction of HC emissions by $65 \%$ for all researched range of load. Ulusoy et al. [30] obtained reductions of HC emissions between $30.66 \%$ and $63.33 \%$ using biodiesel from used frying oil in a four-cylinder, four-stroke, $46 \mathrm{~kW}$ power capacity diesel engine.

The mixture RO20, RO50 and RO75 has smaller HC emissions relative to DF up to 48\% (load 85\% at $1850 \mathrm{rpm}$ ), $49 \%$ (load $90 \%$ at $1900 \mathrm{rpm}$ ) and $63 \%$ (load $90 \%$ at $1800 \mathrm{rpm}$ ) respectively. Similar values of $\mathrm{HC}$ emissions can be also found in the experiments conducted by Nwafor [31] who, by using mixtures of rapeseed oil and diesel, obtained a decrease of $\mathrm{HC}$ emissions of up to $60 \%$ and by Last et. al [32] who tested biodiesel from soybean oil in percentages of $10 \%, 20 \%, 30 \%, 50 \%$ and $100 \%$, thus obtaining $\mathrm{HC}$ reductions between $28 \%$ and $75 \%$. For engine loads $70 \%, 75 \%$ and $80 \%$, there can be noticed close or even higher values of hydrocarbon emissions for the mixtures RO20 and RO50.These increases have values up to $64 \%$ for RO20 (for the engine load of $70 \%$ and $1500 \mathrm{rmp}$ ), $59.5 \%$ for RO50 (for the engine load of 70\% and 1350rpm) and 19\% for RME (engine load of $80 \%$ and 1700rpm). This tendency of growth for $\mathrm{HC}$ emissions is in accordance with the experiments conducted by Labeckas and Slavinskas [19] with pure rapeseed oil for different loads. 

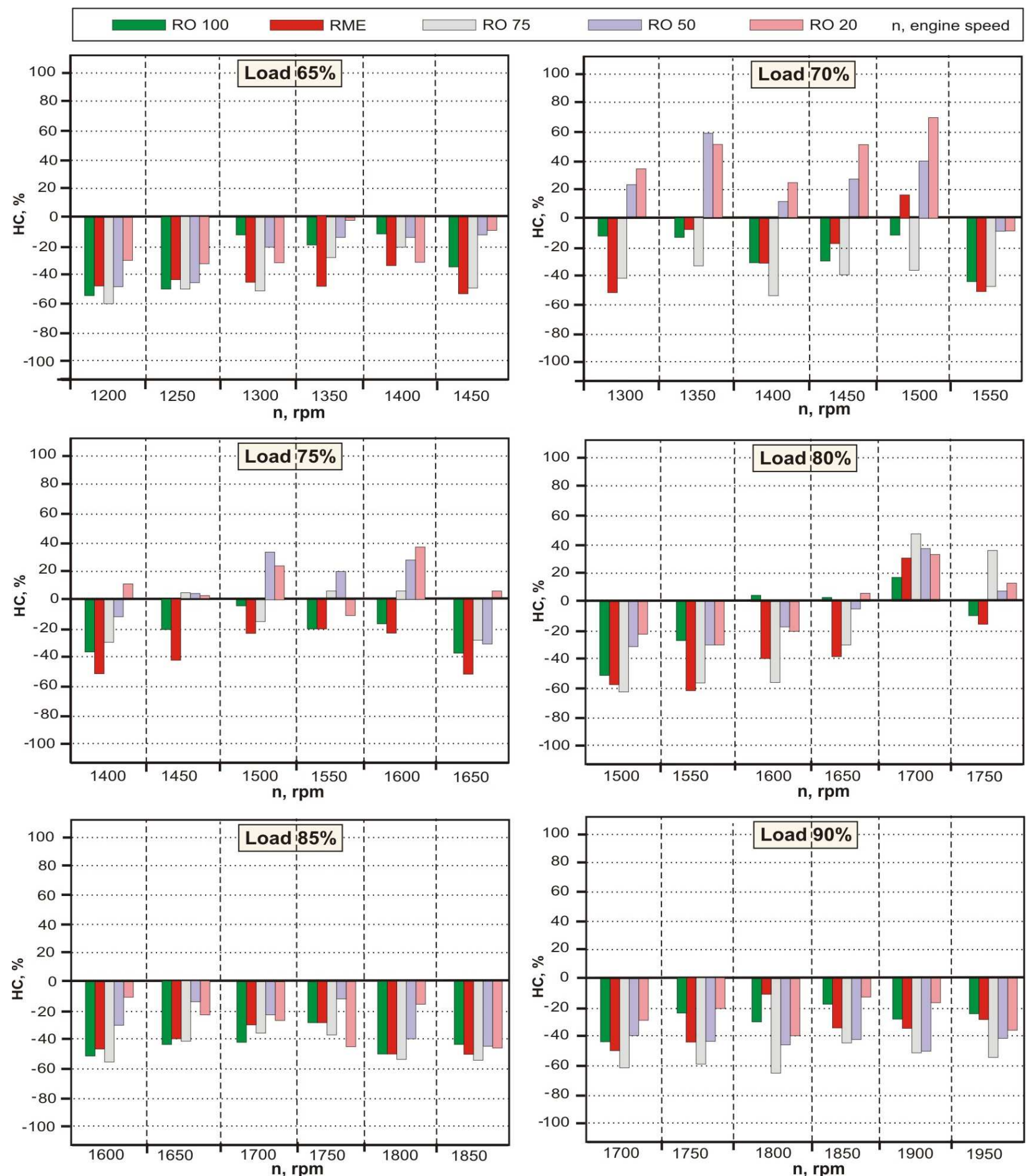

Fig. 4. HC emissions as a function of load at various engine speeds relative to the diesel fuel.

The same thing can be also noticed in the experiments conducted by Bajpai et al. [33] who used on a mono-cylinder diesel engine karanja oil and its mixtures with diesel fuel and concluded that the hydrocarbon emissions for all used fuels increase. The same tendency can also be noticed in the experiments conducted by Labeckas and Slavinskas [13] where, for a load of 70\% engine speed of $2200 \mathrm{rot} / \mathrm{min}$ the values of hydrocarbon emissions for the mixtures RO25, RO50 and RO75 are close to or higher than the ones of diesel fuel. Murillo et al. [34] found that although the biodiesel fuel is less volatile than the diesel fuel, higher final distillation points have been reported for the diesel fuel. This final fraction of the diesel may not be completely vaporized and burnt, thereby increasing $\mathrm{HC}$ emissions. The relative quantity of fuel in the area of non-inflammable mixtures depends on the proportion of fuel injected in the delay period at the beginning of ignition and on the mixture speed. The increase of the delay will lead to a tendency of increase in the HC emissions in the case of the experimental mixtures. 
Upon analyzing figures 3 and 4, a close interdependency between the $\mathrm{HC}$ and $\mathrm{NO}_{\mathrm{x}}$ emissions can be noticed. Thus, the following aspects have been observed:

- The decrease of HC emissions, especially for high loads, when due to the increase of pressure in the combustion chamber the ignition is more complete in comparison with the one for lower loads;

- The ignition is more complete, leading to higher temperatures in the ignition chamber, which determines the formation of $\mathrm{NO}_{\mathrm{x}}$ and the increase of these types of emissions.

\section{Conclusions}

As a result of the experimental research, it can be noticed that the values of pollutant emissions of $\mathrm{NO}_{\mathrm{x}}$ and $\mathrm{HC}$ of the fuels based on rapeseed oil are smaller or very close to the emissions of diesel fuel for most of the load regimes. The determination of the chemical and physical properties of the bio-fuels has been achieved in order to notice their significant differences relative to the diesel fuel. These properties of the used fuels directly influence the fuels combustion (the mixture air-fuel, the penetration of the jet into the combustion chamber), thus having as result the different values of the $\mathrm{NO}_{\mathrm{x}}$ and $\mathrm{HC}$ emissions:

- The most important decrease relative to diesel of $\mathrm{NO}_{\mathrm{x}}$ emissions is for $\mathrm{RO} 100$ for the engine load of $65 \%$ and $1200 \mathrm{rpm}(-53 \%)$. The mixtures RO20, RO50, RO75 insure an obvious decrease of emissions relative to DF for low engine loads (65\% and 70\%) up to $26 \%$ for RO20 (at engine load of $70 \%$ and $1500 \mathrm{rpm}$ ), $29 \%$ for RO50 (at engine load of $65 \%$ and $1450 \mathrm{rpm}$ ) and $28 \%$ for RO75 (at engine load of $70 \%$ and $1300 \mathrm{rpm}$ ), respectively. For RME, the maximum increase for $\mathrm{NO}_{\mathrm{x}}$ emissions in case of RME is $26 \%$ and the decrease is up to $28 \%$.

- The HC emissions for biodiesel fuels remain at a considerably low level ranging with the loads and engine speeds. RO100 has an evolution of $\mathrm{HC}$ emissions between $-53 \%$ and $+8.5 \%$ relative to diesel fuel and the mixture RO20, RO50 and RO75 has smaller HC emissions as compared with diesel fuel up to $48 \%, 49 \%$ and $63 \%$, respectively. RME has a reduction of $\mathrm{HC}$ emission up to $60.5 \%$.

The results of these researches reveal the fact that vegetable oils have a significant influence on the decrease of the emissions of $\mathrm{NO}_{\mathrm{x}}$ and $\mathrm{HC}$ when using them on diesel medium power engines. Still, it is suggested that future researches should focus on the endurance tests of the use of vegetable fuels as diesel fuels in order to identify some additives for reducing the usage and the coating resulted after their use on diesel engines.

\section{Acknowledgements}

This paper was supported by the project "Development and support of multidisciplinary postdoctoral programmes in major technical areas of national strategy of Research - Development Innovation" 4D-POSTDOC, contract no. POSDRU/89/1.5/S/52603, project co-funded by the European Social Fund through Sectoral Operational Programme Human Resources Development 2007-2013.

\section{References}

[1] Barabás, I., Todoruţ, I.A., Predicting the Temperature Dependent Viscosity of BiodieselDiesel-Bioethanol Blends, Energy Fuels, Article ASAP, (2011) DOI: 10.1021/ef2007936.

[2] Devan, P.K., Mahalakshmi, N.V., A study of the performance, emission and combustion characteristics of a compression ignition engine using methyl ester of paradise oil-eucalyptus oil blends, Appl Energy 86, (2009) 675-80.

[3] Ma, F., Hanna, M.A., Biodiesel production: a review, Bioresour Technol 70, (1999) 1-15. 
[4] Sidibé, S.S., Blin, J., Vaitilingom, G., Azoumah, Y., Use of crude filtered vegetable oil as a fuel in diesel engines state of the art: Literature review, Renewable and Sustainable Energy Reviews 14, (2010) 2748-2759.

[5] Labeckas, G., Slavinskas, S., Performance of direct-injection off-road diesel engine on rapeseed oil, Renew Energy 31, (2006) 849-863.

[6] He, Y., Bao, Y.D., Study on rapeseed oil as alternative fuel for a single-cylinder diesel engine. Renew. Energy 28, (2003) 1447-53.

[7] Misra, R.D., Murthy, M.S., Performance, emission and combustion evaluation of soapnut oildiesel blends in a compression ignition engine, Fuel, (2011) 2514-2518.

[8] McDonnell, K.P., Ward ,S.M., McNulty, P.B., Howard-Hildige, R., Results of engine and vehicle testing of semi-refined rapeseed oil, Trans ASAE 43, (2000) 1309-16.

[9] Graboski, M.S., McCormick, R.L., Combustion of fat and vegetable oil derived fuels in diesel engines, Prog Energy Combust Sci 24, (1998) 125-164.

[10] Labeckas, G., Slavinskas, S., The effect of rapeseed oil methyl ester on direct injection Diesel engine performance and exhaust emissions, Energy Conversion and Management 47, (2006) 1954-1967.

[11] Krahl, J., Munack, A., Schröder, O., Stein, H., Dutz, M., Exhaust gas emissions and health effects from biodiesel, fossil diesel fuel, and Swedish low sulphur diesel fuel MKI, Paper Number: 02-6082. An ASAE Annual International Meeting Presentation, Chicago, IL, USA, (2002) 28-31. p.13.

[12] Thuneke, K., Rapeseed Oil Fuel - Production, Quality Demands and Use Experience. Biomass for Energy - Challenges for Agriculture, September 25-26, Bruges, Belgium [online] [10.04.2009], (2006) information on: http://www.northseabioenergy.org /files/17397/Klaus_Thunek pdf.

[13] Labeckas, G., Slavinskas, S., Performance and exhaust emissions of direct-injection diesel engine operating on rapeseed oil and its blends with diesel fuel, Transport, vol XX nr. 5, (2005) 186-194.

[14] Peterson, C.L., Reece, D.L., Emissions testing with blends of esters of rapeseed oil fuel with and without a catalytic converter, SAE paper, (1996) 961114.

[15] Alam, M., Song, J., Zello, V., Boehman, A., 2006. Spray and combustion visualization of a direct-injection diesel engine operated with oxygenated fuel blends. Int J Engine Res 7: 50321.

[16] Ghelbes Heft 69, Begleitforschung zur Standardisierung von Rapsöl als Kraftstoff für pflanzenöl-taugliche Dieselmotoren in Fahrzeugen und BHKW, Landtechnische Berichte aus Praxis und Forschung, München, 2000.

[17] Barabás, I., Todoruţ, A., Băldean, D., Performance and emission characteristics of an CI engine fueled with diesel-biodiesel-bioethanol blends, Fuel, 89(12), (2010) 3827-3832.

[18] Labeckas, G., Slavinskas, S., Study of exhaust emissions of direct injection diesel engine operating on ethanol, petrol and rapeseed oil blends, Energy Conversion and Management 50, (2009) 802-812.

[19] Dorado, M.P., Ballesteros, E., Arnal, J.M., Gómez, J., López, F., Exhaust emissions form a Diesel engine fueled with transesterified waste olive oil, Fuel 82 (2003) 1311-5.

[20] Lapuerta, M., Armas, O., Ballesteros, R., Fernandez, J.. Diesel emissions from biofuels derived from Spanish potential vegetable oils. Fuel 84, (2005) 773-80.

[21] Bhupendra, S.C., Naveen, K., Haeng, M.C., Performance and emission studies on an agriculture engine on neat Jatropha oil, Journal of Mechanical Science and Technology 24 (2), (2010) 529-535.

[22] Saravanan, S., Nagarajan, G., Ramanujam, R., Sampath, S., Controlling $\mathrm{NO}_{\mathrm{x}}$ Emission of Crude Rice Bran Oil Blend for Sustainable Environment, Clean - Soil, Air, Water 2011, 39 (6), (2011) 515-521. 
[23] Gwi-Taek, J., Young-Taig, O., Don-Hee, P., Emission Profile of Rapeseed Methyl Ester and Its Blend in a Diesel Engine, Applied Biochemistry and Biotechnology, ABAB Symposium, Session 1A, (2006) 165-178.

[24] Lebedevas, S., Vaicekauskas, A., Lebedeva, G., Janulis, P., Makarevienė, V., Research into operational parameters of diesel engines running on RME biodiesel. Transport, vol. XXI, No. 4, (2006) 260-268.

[25] Raslavičius, L., Bazaras, Ž., Ecological assessment and economic feasibility to utilize first generation biofuels in cogeneration output cycle - The case of Lithuania, Energy 35, (2010) 3666-3673.

[26] Raslavičius, L., Strakšas, A., Motor Biofuel-Powered CHP Plants-A Step Towards Sustainable Development of Rural Lithuania, Technological and Economic Development of Economy 17(1), (2011) 189-205.

[27] Monyem A, Van Gerpen JH., The effect of biodiesel oxidation on engine performance and emissions, Biomass Bioenergy, 20, (2001) 317-25;

[28] Staat F., Gateau P., The effect of rapeseed oil methyl ester on diesel engine performance, exhaust emissions and long term behaviour-a summary of three years of experimentation, SAE paper, (1995) 950053.

[29] Assesement and Standards Divisions (Office of Transporation and Air Quality of the US Environmental Protection Agency), A comprehensive analysis of biodiesel impact on exhaust emissions, (2002) EPA420-P-02-001.

[30] Ulusoy, Y., Tekin, Y., Çetinkaya, M., and Karaosmanŏglu, F., The engine tests of biodiesel from used frying oil, Energy Sources 26, (2004) 927-932.

[31] Nwafor, O.M.I,. Emission characteristics of diesel engine operating on rapeseed methyl ester. Renew Energy 29, (2004) 119-29.

[32] Last, R.J, Krüger, M., Dürnholz, M., Emissions and performance characteristics of a 4-stroke, direct injected diesel engine fueled with blends of biodiesel and low sulfur diesel fuel, SAE paper, (1995) 950054.

[33] Bajpai, S., Sahoo P.K., Das, L.M., Feasibility of blending karanja vegetable oil in petro-diesel and utilization in a direct injection diesel engine, Fuel 88, (2009) 705-11.

[34] Murillo, S., Míguez, J.L, Porteir,o J., Granada E, Morán, J.C., Performance and exhaust emissions in the use of biodiesel in outboard diesel engines, Fuel 86, (2007) 1765-71. 